\title{
Nano-structure design of doped ceria solid electrolytes for intermediate temperature operation of solid oxide fuel cell
}

\author{
Toshiyuki Mori ${ }^{*},{ }^{1)}$ Ding Rong Ou, ${ }^{1)}$ Fei Ye, ${ }^{1)}$ Jin Zou, ${ }^{2)}$ \\ John Drennan ${ }^{2)}$, and Alstair N. Cormack ${ }^{3)}$ \\ 1) Fuel Cell Materials Center, National Institute for Materials Science, 1-1. Namiki, Ibaraki, Tsukuba, 305-0044 Japan \\ 2) Centre for Microscopy and Microanalysis, The University of Queensland, Brisbane, Qld 4072, Australia \\ 3) Kazuo Inamori School of Engineering, Alfred University, Alfred, NY 14802, USA \\ Corresponding author, Fax: 81-29-860-4667, e-mail: MORI.Toshiyuki@nims.go.jp
}

\begin{abstract}
Doped ceria $\left(\mathrm{CeO}_{2}\right)$ compounds are fluorite related oxides which show oxide ionic conductivity higher than yttria-stabilized zirconia in oxidizing atmosphere. As a consequence of this, considerable interest has been shown in application of these materials for 'intermediate temperature $\left(300-500^{\circ} \mathrm{C}\right)^{\prime}$ operation of solid oxide fuel cells (SOFCs). In this review paper, our experimental data was re-introduced to propose a new design paradigm for development of high quality doped $\mathrm{CeO}_{2}$ electrolytes. Based on our experimental data, our original idea a control of nano-inhomogeity of doped $\mathrm{CeO}_{2}$ electrolytes was proposed. In our work, the nano-sized powders and dense sintered bodies of $\mathrm{M}$ doped $\mathrm{CeO}_{2}(\mathrm{M}$ : $\mathrm{Sm}, \mathrm{Gd}, \mathrm{Y}, \mathrm{Yb}$, $\mathrm{Dy}, \mathrm{Ho}, \mathrm{Tb}$ and $\mathrm{La}$ ) specimens were fabricated using ammonium carbonate co-precipitation method, conventional sintering method and pulsed electric current sintering method. Also nano-structural features of those specimens were carefully observed for conclusion of relationship between electrolytic properties and microstructure in doped $\mathrm{CeO}_{2}$. It is essential that the electrolytic properties of doped $\mathrm{CeO}_{2}$ reflect in changes of microstructure even down to the atomic scale. Accordingly, a combined approach of ultimate analysis, simulation and processing route design is required to develop the superior quality doped $\mathrm{CeO}_{2}$ electrolytes for the intermediate temperature operation of SOFCs.
\end{abstract}

Keywords: Doped $\mathrm{CeO}_{2}$, Oxide ionic conductivity, Micro-domain, Intermediate temperature operation of SOFCs, Nano-inhomogeneity,

\section{Introduction}

Over the past 50 years, the potential of materials with fast oxide ionic conduction has been realized in many applications. Oxide ion conductors are used in a variety of gas sensors, ${ }^{[1-4]}$ solid oxide electrochemical cells (SOECs), ${ }^{[5-7]}$ and solid oxide fuel cells (SOFCs). ${ }^{[8-12]}$ In those applications, SOFCs are being especially developed as a clean and efficient power source for generating electricity from a variety of fuels. For long lifetimes and efficient operation at 'intermediate temperature $\left(300^{\circ}-500^{\circ} \mathrm{C}\right)^{\prime}$, high oxide ionic conductivity is required for the development of electrolytes. The 'intermediate temperature' operation of SOFCs means that less expensive materials can be used as interconnects, manifolds and gas transport systems. Yttria stabilized zirconia (YSZ) and scandia stabilized zirconia (SSZ) are common electrolytes used in SOFCs. However, its ionic conductivity is still unsatisfactory for intermediate temperature operation of SOFCs. Accordingly, it is important that a high-quality electrolyte with higher oxide ionic conductivity than that of YSZ and SSZ be identified.

$\mathrm{CeO}_{2}$ doped with the oxides of divalent metal oxide such as calcia or rare earth oxide (yttria $\left(\mathrm{Y}_{2} \mathrm{O}_{3}\right)$, gadolia $\left(\mathrm{Gd}_{2} \mathrm{O}_{3}\right)$, and so on) doped ceria $\left(\mathrm{CeO}_{2}\right)$ compounds possess higher oxide ionic conductivity than any reported stabilized zirconia. ${ }^{[13-17]}$ At high oxygen partial pressures, those doped $\mathrm{CeO}_{2}$ electrolytes show high oxide ionic conductivity. At low oxygen partial pressures associated with anodic conditions, however, the $\mathrm{Ce}^{4+}$ ion can be partially reduced to $\mathrm{Ce}^{3+}$ ion in doped $\mathrm{CeO}_{2}$. Quasi-free electrons are introduced into a fluorite lattice in such reducing atmospheres. Doped $\mathrm{CeO}_{2}$ compounds are partially reduced and develop electronic conductivity under anodic conditions in the fuel cell. The stability in both oxidizing and reducing atmosphere is an essential requirement for candidate electrolytes rare earth doped $\mathrm{CeO}_{2}$ systems. To overcome this problem and improve the conductivity for 'intermediate temperature' operation of SOFCs, a design of nano-structure in doped $\mathrm{CeO}_{2}$ solid electrolytes is required. In the present short review paper, the authors 
re-introduce our works on the basis of a micro-analysis of the doped $\mathrm{CeO}_{2}$ electrolytes and suggest a new design paradigm for fabrication of nano-structured doped- $\mathrm{CeO}_{2}$ solid electrolytes for application of 'intermediate temperature' operation of SOFCs. In our new challenge, a control of nano-inhomogeneity in doped $\mathrm{CeO}_{2}$ is a key for development of our new design paradigm. We expect that combination of a control of processing route of doped $\mathrm{CeO}_{2}$ ceramics, atom-level observation of the microstructure and simulation of nano-structural feature of the doped $\mathrm{CeO}_{2}$ solid electrolytes will clarify the best pathway for development of high quality doped $\mathrm{CeO}_{2}$ solid electrolytes in intermediate temperature operation of SOFCs.

\section{Microanalysis of doped $\mathrm{CeO}_{2}$ electrolytes}

$\mathrm{CeO}_{2}$ electrolytes doped with tri-valent rare earth cation or di-valent alkaline earth cation have been widely investigated. The additives produce materials with extensive solid solubility in the fluorite $\mathrm{CeO}_{2}$ lattice. The relationships among physical, chemical, electrochemical properties, dopant size, and dopant content in $\mathrm{CeO}_{2}$ electrolytes were widely examined before. ${ }^{[14-16]}$ It has been considered that aforementioned doped $\mathrm{CeO}_{2}$ electrolytes exhibited high oxide ionic conductivity due to the small association enthalpy between dopant cation and oxygen vacancy in the fluorite lattice. However, these arguments lacked an important viewpoint from careful micro-analysis in doped $\mathrm{CeO}_{2}$ electrolytes. The prospective improvements in the electrolytic properties (i.e. conductivity, activation energy, oxygen partial pressure dependence of conductivity and so on) of doped $\mathrm{CeO}_{2}$ would be limited. In light of this limitation, a careful atom-level observation is required for development of doped $\mathrm{CeO}_{2}$.

The authors examined the relationship among oxide ionic conductivity, dopant content and microstructural features of $\mathrm{Y}$ doped $\mathrm{CeO}_{2}$ electrolyte. ${ }^{[18-20]}$ The conductivity showed the maximum at the composition around $\mathrm{x}=0.15$ in $\mathrm{Y}_{\mathrm{x}} \mathrm{Ce}_{1-\mathrm{x}} \mathrm{O}_{2-\mathrm{x} / 2}(\mathrm{x}=0.1,0.15,0.2$ and 0.25$)$ system. Also, the activation energy of $\mathrm{Y}$ doped $\mathrm{CeO}_{2}$ electrolytes was minimized at the same composition (i.e. Y: 15at.\%) in $\mathrm{CeO}_{2}$ doped with $\mathrm{Y}$ system. This indicates that the mobility of oxide ion is maximized at the aforementioned composition in the $\mathrm{Y}_{\mathrm{x}} \mathrm{Ce}_{1-\mathrm{x}} \mathrm{O}_{2-\mathrm{x} / 2}$ system. To conclude why the conductivity and activation energy have optimum value in $\mathrm{Y}$ doped $\mathrm{CeO}_{2}$, the crystal phase and nano-structural features in the sintered bodies were examined.

To fabricate the dense sintered bodies of $\mathrm{Y}_{\mathrm{x}} \mathrm{Ce}_{1-\mathrm{x}} \mathrm{O}_{2-\mathrm{x} / 2}(\mathrm{x}=0.1,0.15,0.2$, and 0.25$)$, the nano-sized easy sinterable powders were prepared using soft chemical approach (Fig.1(a)). Also dense sintered bodies were fabricated using those calcined powders as shown in Fig.1(a). X-ray diffraction profiles recorded from those sintered bodies consist of simple fluorite structure (Fig.1(b)), but the selected area electron

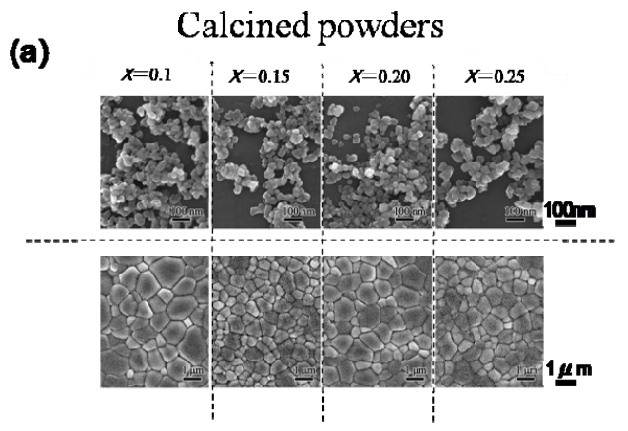

Sintered bodies

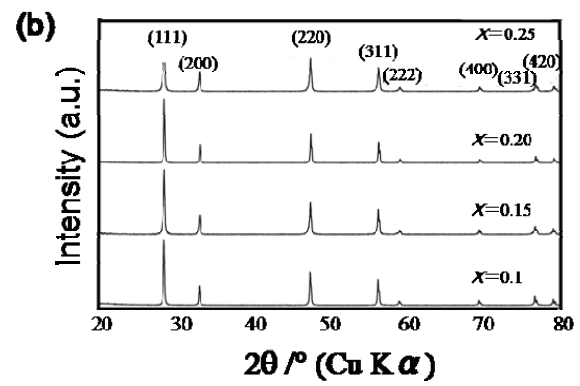

Figure 1 (a) Scanning electron microscope (SEM) photographs of calcined powders, sintered bodies of $\mathrm{Y}_{\mathrm{x}} \mathrm{Ce}_{1-\mathrm{x}} \mathrm{O}_{2-\mathrm{x} / 2}$, (b) X-ray diffraction patterns recorded from $\mathrm{Y}_{\mathrm{x}} \mathrm{Ce}_{1-\mathrm{x}} \mathrm{O}_{2-\mathrm{x} / 2}$ calcined powders. Calcination temperature: $700^{\circ} \mathrm{C} .{ }^{[19]}$

diffraction patterns (SAEDPs) recorded from $\mathrm{Y}_{\mathrm{x}} \mathrm{Ce}_{1-\mathrm{x}} \mathrm{O}_{2-\mathrm{x} / 2}(\mathrm{x}=0.1,0.15,0.2$ and 0.25$)$ sintered bodies have diffuse scattering in the background of SAEDPs (Fig.2). The intensity of extra reflection and diffuse scattering in SAEDP of $\mathrm{Y}_{0.25} \mathrm{Ce}_{0.75} \mathrm{O}_{1.875}$ is much stronger than that of $\mathrm{Y}_{0.15} \mathrm{Ce}_{0.85} \mathrm{O}_{1.925}$.
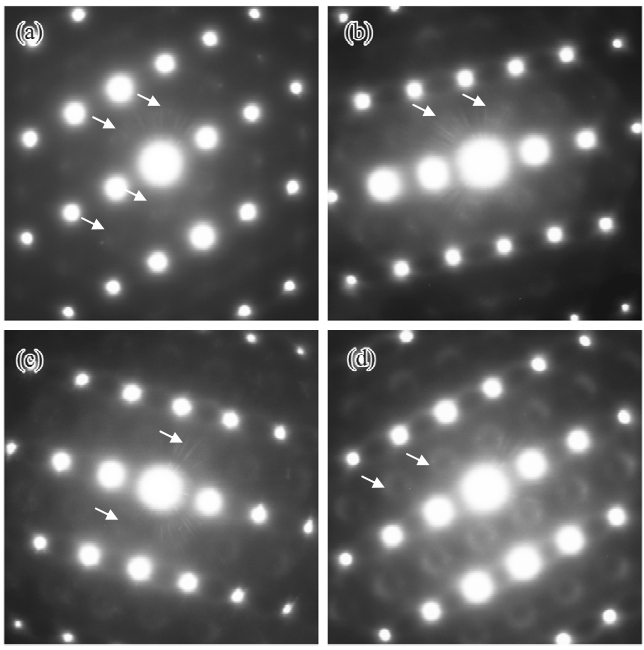

Figure 2 Selected area electron diffraction patterns (SAEDPs) recorded from $\mathrm{Y}_{\mathrm{x}} \mathrm{Ce}_{1-\mathrm{x}} \mathrm{O}_{2-\mathrm{x} / 2}$ $(x=0.1,0.15,0.2$ and 0.25$)$ sintered bodies, (a) $x=0.1$, (b) $x=0.15$, (c) $x=0.2$, (d) $x=0.25$, white arrows indicate diffuse scattering in the background of SAEDPs. ${ }^{[19]}$ 
This indicates that all observed specimens have the micro-domains with ordered structure of oxygen vacancies. The micro-domain size in $\mathrm{Y}_{0.25} \mathrm{Ce}_{0.75} \mathrm{O}_{1.875}$ is bigger than that in $\mathrm{Y}_{0.15} \mathrm{Ce}_{0.85} \mathrm{O}_{1.925}$.

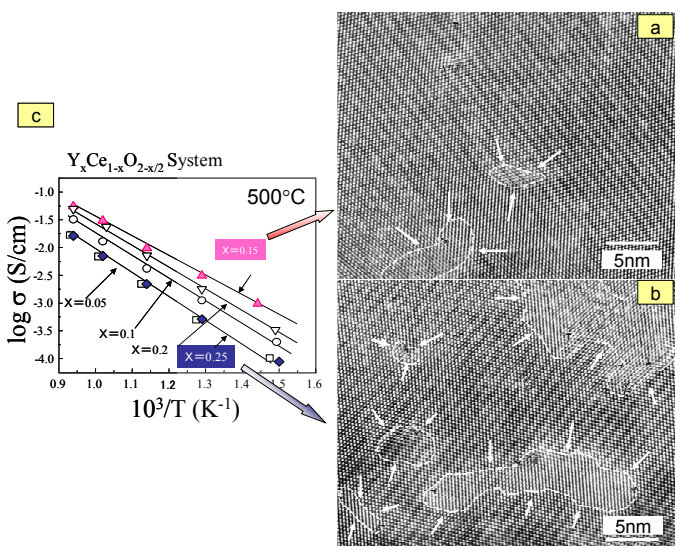

Figure 3 Relationship between conductivity and microstructural features of $\mathrm{Y}$ doped $\mathrm{CeO}_{2}$ solid electrolytes. (a): microstructure at atomic scale of $\mathrm{Y}_{0.15} \mathrm{Ce}_{0.85} \mathrm{O}_{1.925}$ sintered body with high conductivity, (b): microstructure at atomic scale of $\mathrm{Y}_{0.25} \mathrm{Ce}_{0.75} \mathrm{O}_{1.875}$ sintered body with low conductivity, white arrows and white dashed line area indicate the micro-domains and (c): Arrhenius plots of conductivity. ${ }^{[21]}$

To conclude the relationship between micro-domain structure and conducting properties of doped $\mathrm{CeO}_{2}$ solid electrolytes in detail, microstructural features and temperature dependence of conductivity of $\mathrm{Y}$ doped $\mathrm{CeO}_{2}$ system were examined as shown in Fig.3. Our high resolution - transmission electron microscopy (HR-TEM) shows us that $\mathrm{Y}_{0.25} \mathrm{Ce}_{0.75} \mathrm{O}_{1.875}$ sintered body with low conductivity includes lots of big messy region so called micro-domain in the microstructure, and a size of the micro-domains in $\mathrm{Y}_{0.15} \mathrm{Ce}_{0.85} \mathrm{O}_{1.925}$ sintered body with high conductivity was much smaller than that of $\mathrm{Y}_{0.25} \mathrm{Ce}_{0.75} \mathrm{O}_{1.875}$. Those indicate that the conductivity in doped $\mathrm{CeO}_{2}$ solid electrolytes is influenced by the micro-domain size. Also HR-TEM images of aforementioned specimens agree with the conclusion in Fig.2. The dopant cations would aggregate together and precipitate from the matrix. The oxygen vacancies would be deeply trapped by those micro-domains and be arranged with short-ranged orders in the matrix of $\mathrm{CeO}_{2}$. Therefore, the authors concluded that the micro-domain size and micro-domain content impacted on the conducting properties in doped $\mathrm{CeO}_{2}$. The big micro-domain would lower the conducting properties in $\mathrm{Y}$ doped $\mathrm{CeO}_{2}$ solid electrolytes.

In the previous work about relationship between dopant concentration and conducting properties of doped $\mathrm{CeO}_{2}$, the ionic radius mismatch between dopant and host cation Ce was discussed. According to this concept, $\mathrm{Gd}_{0.2} \mathrm{Ce}_{0.8} \mathrm{O}_{1.9}$ can show the highest conductivity and lowest activation energy in all doped $\mathrm{CeO}_{2}$ series. It is because ionic radius mismatch between $\mathrm{Gd}$ and $\mathrm{Ce}$ reaches the minimum and the binding energy of oxygen vacancy and cation becomes a minimum as well. ${ }^{22-24}$ This concept well explained why the maximum conductivity was changed by the variety of dopant cation in $\mathrm{CeO}_{2}$ doped with $20 \%$ dopant cation. Also the similar tendency was observed in other fluorite systems. ${ }^{25}$ In the $\mathrm{ZrO}_{2}$ based system, a part of tetravalent $\mathrm{Zr}$ cation site has to be substituted by another cation such as $\mathrm{Ca}^{2+}, \mathrm{Sc}^{3+}$, and $\mathrm{Y}^{3+}$. In this system, the ionic radius ratio between $\mathrm{Zr}^{4+}$ and aforementioned dopant cation plays a major role to increase the oxide ionic conductivity. The oxide ionic conductivity increases when the ionic radius becomes close to $\mathrm{Zr}^{4+}$ (ionic radius of $\mathrm{Zr}^{4+}$ for oxygen eight hold coordination: $0.84 \AA$ ). The best ionic radius of dopant is reached for $\mathrm{Sc}^{3+}$ (ionic radius of $\mathrm{Sc}^{3+}$ for oxygen eight hold coordination: $0.87 \AA$ ) with a conductivity equal to $10^{-1} \mathrm{~S} / \mathrm{cm}$ at $800^{\circ} \mathrm{C}$ for $10 \% \quad \mathrm{Sc}_{2} \mathrm{O}_{3}$ doped $\mathrm{ZrO}_{2}$. This conductivity of $\mathrm{Sc}_{2} \mathrm{O}_{3}$ doped $\mathrm{ZrO}_{2}$ is much higher than $10 \% \mathrm{Y}_{2} \mathrm{O}_{3}$ doped $\mathrm{ZrO}_{2}\left(3 \times 10^{-2} \mathrm{~S} / \mathrm{cm}\right)$ at the same measurement temperature. Also $\mathrm{Bi}_{2} \mathrm{O}_{3}$ based oxides show the similar tendency. In the case of $\mathrm{Bi}_{2} \mathrm{O}_{3}$ based system, $\delta$-fcc forms are high oxide ionic conductors. The polymorphism of $\mathrm{Bi}_{2} \mathrm{O}_{3}$ based materials depends on ionic radius of dopant cation. When the ionic radius ratio between dopant cation and Bi becomes 0.9 to 0.95 , $\delta$ cubic phase is appeared.



Figure 4 (a) grain size dependence of conductivity of $\mathrm{Y}$ doped $\mathrm{CeO}_{2} \cdot{ }^{[26]}$

Those results suggest that microstructure at atomic scale can be linked to conducting properties in fluorite type oxide ionic conductors. In the concept of ionic radius mismatch, however, it is not so easy to explain why the lowering of conductivity from $\mathrm{Gd}_{0.15} \mathrm{Ce}_{0.85} \mathrm{O}_{1.925}$ to $\mathrm{Gd}_{0.25} \mathrm{Ce}_{0.75} \mathrm{O}_{1.875}$ is much bigger than that of $\mathrm{Y}_{0.15} \mathrm{Ce}_{0.85} \mathrm{O}_{1.925}$ to $\mathrm{Y}_{0.25} \mathrm{Ce}_{0.75} \mathrm{O}_{1.875}$. For a conclusion of relationship between dopant concentration and conducting properties of doped $\mathrm{CeO}_{2}$, an actual microstructure in doped $\mathrm{CeO}_{2}$ 
should be taken into account. Based on the results of our micro-analysis, we concluded why the conductivity of $\mathrm{Gd}_{0.25} \mathrm{Ce}_{0.75} \mathrm{O}_{1.875}$ was lower than $\mathrm{Y}_{0.25} \mathrm{Ce}_{0.75} \mathrm{O}_{1.875}$. We briefly introduce our idea on the basis of our micro-analysis results. To conclude the relationships among microstructural features, conductivity, and dopant concentration, the comparison of the grain size dependence of Gd doped $\mathrm{CeO}_{2}$ and $\mathrm{Y}$ doped $\mathrm{CeO}_{2}$ was re-introduced in Fig.4 (a) to (d).

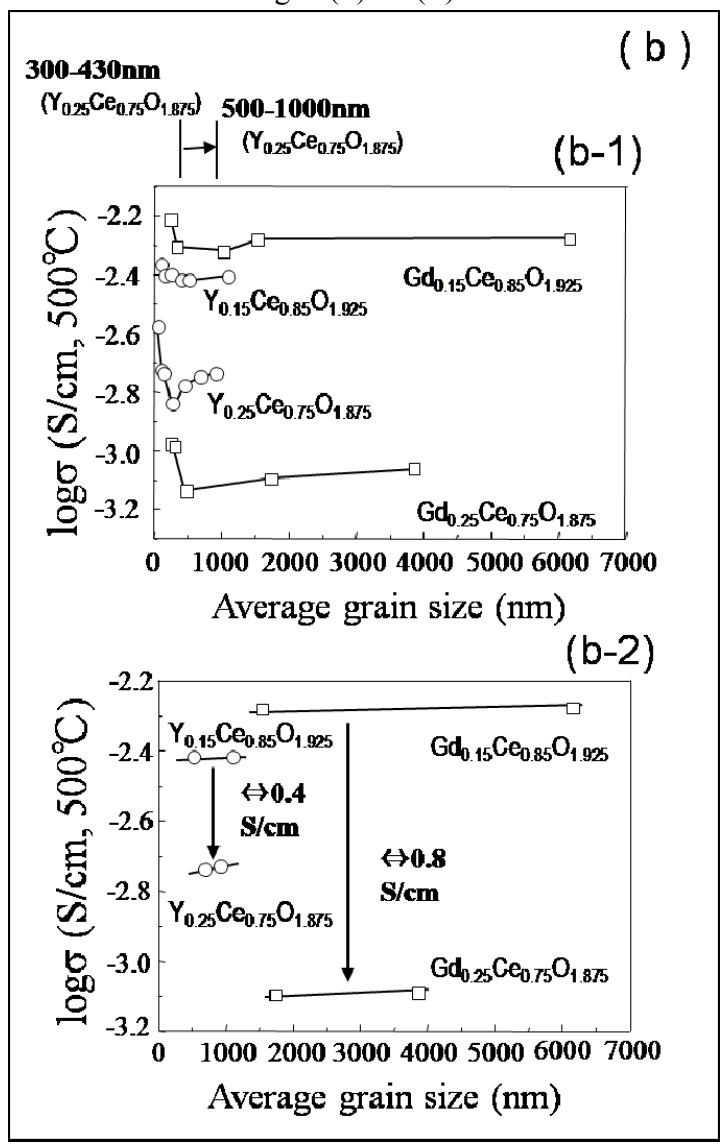

Figure 4 (b) grain size dependence of conductivity of $\mathrm{Gd}$ doped $\mathrm{CeO}_{2} \cdot{ }^{[26]}$

In the case of $\mathrm{Gd}_{0.15} \mathrm{Ce}_{0.85} \mathrm{O}_{1.925}$ and $\mathrm{Y}_{0.15} \mathrm{Ce}_{0.85} \mathrm{O}_{1.925}$, small amount of dopant was aggregated into micro-domains. The dopant concentration into micro-domain was 3 to $5 \%$ higher than that in the matrix (i.e. outside of micro-domain). And the size of micro-domain of $\mathrm{Gd}_{0.15} \mathrm{Ce}_{0.85} \mathrm{O}_{1.925}$ would be smaller than that of $\mathrm{Y}_{0.15} \mathrm{Ce}_{0.85} \mathrm{O}_{1.925}$. The authors will demonstrate micro-domain size difference between those $\mathrm{Gd}$ doped $\mathrm{CeO}_{2}$ and $\mathrm{Y}$ doped $\mathrm{CeO}_{2}$ using TEM pictures in Fig.5 and Fig.6. Based on our microanalysis results, relationship between dopant aggregation level and distance of two micro-domains was illustrated in Fig.4 (c) and (d) In those illustrations, a degree of oxygen vacancy ordering corresponds to dopant agglomeration level. The micro-domain size of $\mathrm{Y}_{0.15} \mathrm{Ce}_{0.85} \mathrm{O}_{1.925}$ is bigger than $\mathrm{Gd}_{0.15} \mathrm{Ce}_{0.85} \mathrm{O}_{1.925}$. And the total amount of aggregation of dopant in the small micro-domain area of $\mathrm{Gd}_{0.15} \mathrm{Ce}_{0.85} \mathrm{O}_{1.925}$ is as almost same as in the $\mathrm{Y}_{0.15} \mathrm{Ce}_{0.85} \mathrm{O}_{1.925}$. Those results indicate that the degree of oxygen vacancy ordering into the micro-domain of $\mathrm{Gd}$ doped $\mathrm{CeO}_{2}$ is higher than $\mathrm{Y}$ doped $\mathrm{CeO}_{2}$. In the microstructure of $\mathrm{Gd}_{0.15} \mathrm{Ce}_{0.85} \mathrm{O}_{1.925}$, there are some clean areas among micro-domains.

(c)

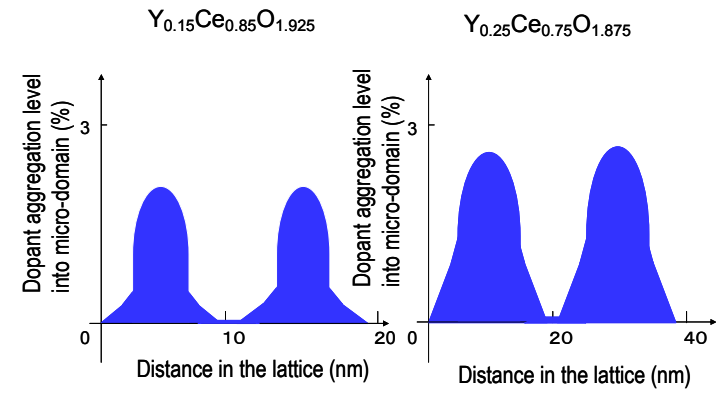

(d)

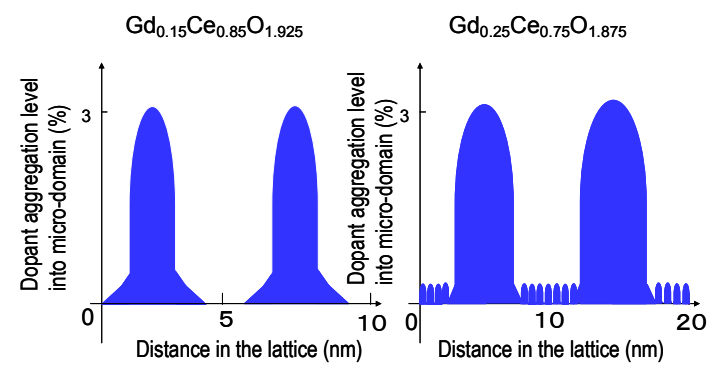

Figure 4(c) and (d) dopant aggregation level into micro-domains of $\mathrm{Y}$ doped $\mathrm{CeO}_{2}$ system (c) and $\mathrm{Gd}$ doped $\mathrm{CeO}_{2}$ system (d).

Therefore, the oxide ion can easily diffuse into the heterogeneous micro-domain structure. On the other hand, the edges of micro-domain area are overlapped in the microstructure of $\mathrm{Y}_{0.15} \mathrm{Ce}_{0.85} \mathrm{O}_{1.925}$ (as shown in Fig.4c). This is why the activation energy of $\mathrm{Gd}$ doped $\mathrm{CeO}_{2}$ is lower than $\mathrm{Y}$ doped $\mathrm{CeO}_{2}$.

In the heavy dopant region (i.e. $\mathrm{Gd}_{0.25} \mathrm{Ce}_{0.75} \mathrm{O}_{1.875}$ ), however, quite small micro-domains would be created between micro-domains of $\mathrm{Gd}_{0.25} \mathrm{Ce}_{0.75} \mathrm{O}_{1.875}$. Then, the mobility of oxide ions in the microstructure of $\mathrm{Gd}_{0.25} \mathrm{Ce}_{0.75} \mathrm{O}_{1.875}$ becomes low. The lowering of conductivity from $\mathrm{Gd}_{0.15} \mathrm{Ce}_{0.85} \mathrm{O}_{1.925}$ to $\mathrm{Gd}_{0.25} \mathrm{Ce}_{0.75} \mathrm{O}_{1.875}$ becomes big as compared with the degradation of conductivity from $\mathrm{Y}_{0.15} \mathrm{Ce}_{0.85} \mathrm{O}_{1.925}$ to $\mathrm{Y}_{0.25} \mathrm{Ce}_{0.75} \mathrm{O}_{1.875}$ (Fig.4a and 4b). As mentioned above, the relationship between dopant concentration and conducting properties of doped $\mathrm{CeO}_{2}$ has to conclude on the basis of careful microanalysis of doped $\mathrm{CeO}_{2}$ solid electrolytes.

To make sure the validity of our conclusion, bright field image and dark field image were displayed in Fig.5. In Fig.5, some brighter areas in the dark field images were much darker in the bright field images. Those contrast changes in both images mean that the chemical composition and local structure in the brighter areas in the dark field images are different from the matrix area of $\mathrm{Y}$ doped $\mathrm{CeO}_{2}$ sintered body. 




Figure 5 Dark field image and bright field image recorded from $\mathrm{Y}_{0.25} \mathrm{Ce}_{0.75} \mathrm{O}_{1.875}$ sintered body with low conducting property.

To compare the size and distribution of micro-domains of $\mathrm{Y}_{0.25} \mathrm{Ce}_{0.75} \mathrm{O}_{1.875}$ and $\mathrm{Gd}_{0.25} \mathrm{Ce}_{0.75} \mathrm{O}_{1.875}$, dark field image and bright field image recorded from $\mathrm{Gd}_{0.25} \mathrm{Ce}_{0.75} \mathrm{O}_{1.875}$ are shown in Fig.6. The microstructural feature of $\mathrm{Gd}$ doped $\mathrm{CeO}_{2}$ was similar to $\mathrm{Y}$ doped $\mathrm{CeO}_{2}$. But brighter areas in the dark field image recorded from $\mathrm{Gd}_{0.25} \mathrm{Ce}_{0.75} \mathrm{O}_{1.875}$ was much smaller than that of $\mathrm{Y}_{0.25} \mathrm{Ce}_{0.75} \mathrm{O}_{1.875}$. Since this type argument is based on preliminary observation of microstructure, we compared the size of micro-domain using high resolution TEM. This TEM observation basically agreed with our preliminary observation. Based on those data, it is concluded that micro-domains size and its distribution are different in the microstructure of

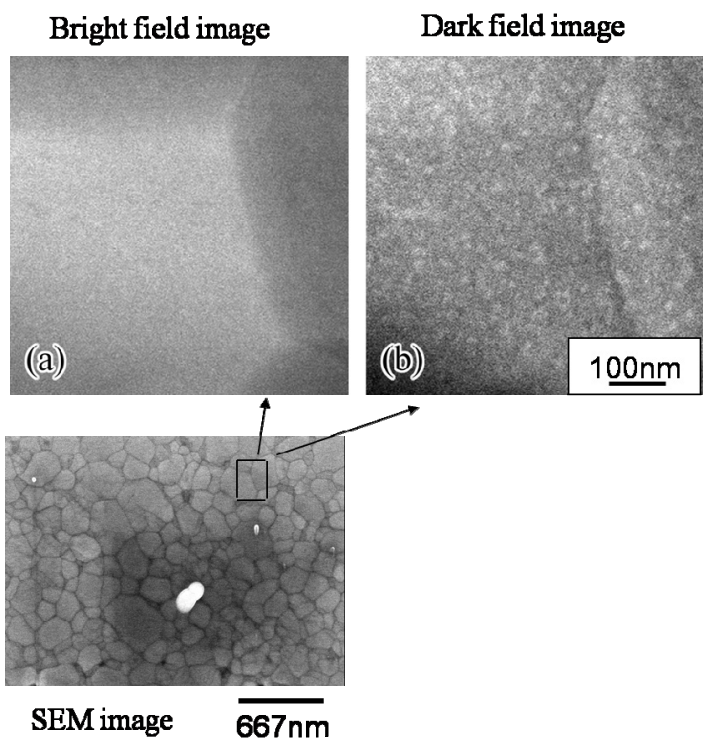

Figure 6 SEM image, bright field (a) and dark field (b) images recorded from $\mathrm{Gd}_{0.25} \mathrm{Ce}_{0.75} \mathrm{O}_{1.875}$ sintered body. each doped $\mathrm{CeO}_{2}$ system. Those are changed by the dopant content. And relationship between dopant content and micro-structural features was summarized as follows. In the dilution region of dopant content (i.e. less than 10\%), size of micro-domain is quite small. But the size of micro-domain becomes big when dopant content is more than $20 \%$ or $25 \%$. Also the super-lattice is observed when dopant content is over $40 \%$ or $50 \%$ in doped $\mathrm{CeO}_{2}$ system.

Moreover, the ordered structure of oxygen vacancy in the microstructure would be changed by the dopant content in doped $\mathrm{CeO}_{2}$. To conclude the influence of oxygen vacancy ordering on conducting properties in the heterogeneous micro-domain structure of doped $\mathrm{CeO}_{2}$, we already started a simulation of ordered oxygen vacancy structure using our simulation method. The authors will touch on this matter in the sections of Fig.9, Fig. 10 and Table 1 in this paper.

Those results suggest that sintered bodies of $\mathrm{CeO}_{2}$ with tri-valent cation are still in a non-equilibrium state. The authors will discuss why the heterogeneous microstructure at atomic scale is observed in doped $\mathrm{CeO}_{2}$ sintered bodies latter. Before that, we must conclude what is micro-domain. What is the different between micro-domain area and matrix area of the grain in the materials? To clarify those points, we compared microstructures into two specimens. One is $\mathrm{Y}_{0.25} \mathrm{Ce}_{0.75} \mathrm{O}_{1.875}$ sintered at $1100^{\circ} \mathrm{C}$, another one is $\mathrm{Y}_{0.25} \mathrm{Ce}_{0.75} \mathrm{O}_{1.875}$ sintered at $1450^{\circ} \mathrm{C}$ (Fig.7).



Figure7 $\mathrm{Ce}$ and $\mathrm{Y}$ element mappings and SAEDPs recorded from $\mathrm{Y}_{0.25} \mathrm{Ce}_{0.75} \mathrm{O}_{1.875}$ sintered at $1450^{\circ} \mathrm{C}$ and $1100^{\circ} \mathrm{C}$. Black arrows indicate aggregation of $\mathrm{Y}$ and $\mathrm{Ce}$ elements in the sintered bodies. [32]

In the specimen sintered at $1100^{\circ} \mathrm{C}$, there were no some interesting micro-structural features. It looks homogeneous. But aggregation of dopant cation $\mathrm{Y}$ was clearly observed in the specimen sintered at $1450^{\circ} \mathrm{C}$. $\mathrm{Y}$ concentration in the micro-domains was about $30 \%$, while Y concentration in the matrix was about $25 \%$. Also 
a big diffuse scattering was observed in the background of SAEDPs recorded from the specimen sintered at $1450^{\circ} \mathrm{C}$. It is concluded that the short range ordering of oxygen vacancy in the heterogeneous microstructure of doped $\mathrm{CeO}_{2}$ creates those big diffuse scattering in the background of SAEDPs. Usually, the short range ordering of oxygen vacancy will be in one unite cell or half cell size. If the ordering of oxygen vacancy made a long chain and gather it into micro-domain area, an ordered structure line can be observed in the XRD profile by Bragg diffraction of X-ray analysis. Therefore, we conclude that there are so many small clusters consisted of oxygen vacancy and dopant cation in the microstructure. Many small oxygen vacancy clusters were gathered into the micro-domain area. Then the diffuse scattering comes up in the background of SAEDPs. In the section of our simulation, the authors will explain this point. Based on our observation results, we propose the following micro-domain formation process.

In general, the easy sinterable powders were prepared for fabrication of dense sintered bodies using soft chemical process (i.e. co-precipitation method, sol-gel method, hydrolysis method and so on). In the case of preparation of solid solution such as trivalent or di-valent cation doped $\mathrm{CeO}_{2}$ system, nano-level inhomogeneity would be still in the calcined powders which are prepared by means of the soft chemical process. In the homogeneous grain growth specimen which is fabricated at lower temperature, the heterogeneity in the grain of sintered body is still low level. In the heterogeneous grain growth specimens which is fabricated at higher temperature such as $1450^{\circ} \mathrm{C}$, however, the heterogeneity is increased by the development of aggregation of dopant in the grain. Then the micro-domain was clearly formed into the grain of doped $\mathrm{CeO}_{2}$ sintered bodies. Since this microstructural change in doped $\mathrm{CeO}_{2}$ sintered body was subtle, relationship between electrolytic properties and nano-structural features has not been examined well. To decrease the nano-level inhomogeneity in the calcined powders, a long time anneal of powders at higher temperature would be effective. But such long annealed powders will lose the good sinterability. That means that processing route for fabrication of fine solid electrolyte powders and dense sintered bodies has to be carefully designed on the basis of microanalysis results. The authors believe that a design of high quality solid electrolytes on the basis of careful microanalysis marks a major breakthrough in the fuel cell field.

For development of our design concept, we must think about the concentration of oxygen vacancies into micro-domain and among the micro-domains in the fluorite matrix of doped $\mathrm{CeO}_{2}$. For our discussion, we need simulation of ordering or clustering of oxygen vacancy in the micro-domain and among the micro-domains. Also we need to discuss about the degree of crystallographic order of the dopant atoms and oxygen vacancies in the microstructure. The authors will touch this point in the section of simulation.

In addition, to design the oxide ionic conductors for fuel cell application, we must think about the influence of the redox state of $\mathrm{Ce}$ on conducting properties. This argument is important for a design of doped $\mathrm{CeO}_{2}$ oxide ionic conductor. Therefore, the authors will explain our results and idea in the parts of Fig.11 to Fig.14.

Before those discussions, we will explain the degree of oxygen vacancy ordering into micro-domain. To analyze it, the oxygen vacancy ordering into the micro-domain was observed by means of electron energy-loss spectroscopy (EELS) analysis method. O K-edge spectra recorded from micro-domain area and matrix area of $\mathrm{Y}_{0.25} \mathrm{Ce}_{0.75} \mathrm{O}_{1.875}$ sintered body were shown in Fig.8. Figure 8 a shows us that peak $\mathrm{B}$ height is much taller than that of peak $\mathrm{C}$. This oxygen vacancy ordering in $\mathrm{Ce}$ doped $\mathrm{Y}_{2} \mathrm{O}_{3}$ and $\mathrm{Y}_{2} \mathrm{O}_{3}$ on $\mathrm{Si}$ was observed using $\mathrm{X}$-ray photoelectron spectroscopy, ${ }^{27} \mathrm{X}$-ray Absorption Spectroscopy ${ }^{27}$ and EELS $^{28}$ before. Those previous works suggested that the degree of oxygen vacancy into $\mathrm{Y}_{2} \mathrm{O}_{3}$ can be characterized using $\mathrm{O}$ K-edge spectra. Since their ideas are quite interesting and explain the microstructural features well, we try to use same characterization method to understand of the micro-domain structure in the doped $\mathrm{CeO}_{2}$. As shown in Fig.8(a), the peak B height was quite different between micro-domain area and matrix area.

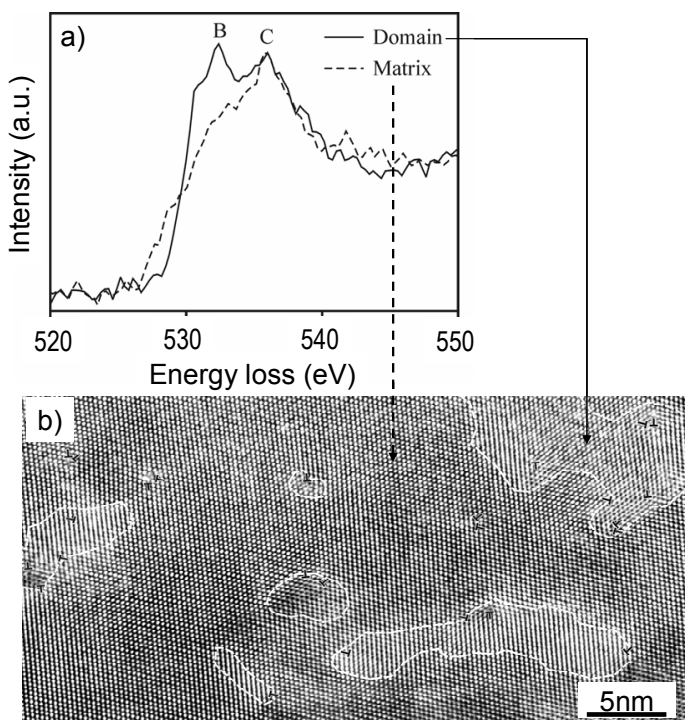

Figure 8 EELS oxygen K-edge spectra recorded from micro-domain area and matrix area of $\mathrm{Y}_{0.25} \mathrm{Ce}_{0.75} \mathrm{O}_{1.875}$ sintered body and HR-TEM image for EELS analysis. Sintering temperature: $1450^{\circ} \mathrm{C}$. ${ }^{[32]}$

This microanalysis leads us to conclude that the degree of oxygen vacancy is higher than the matrix area of fluorite structure. To confirm the 
actual oxygen vacancy structure of micro-domain, however, a simulation of the oxygen vacancy structure in the micro-domain area and in the matrix area among micro-domains is required.

To conclude the oxygen defect structure into and between the micro-domains in doped $\mathrm{CeO}_{2}$, we tried to simulate SAEDPs using Mott-Littleton two-region approach.

In the simulation of F.Ye who is one of authors, ${ }^{20}$ the clusters of oxygen vacancy and dopant cation were assumed into micro-domain of $\mathrm{Gd}$ doped $\mathrm{CeO}_{2}$. In this idea, the micro-domain consists of group of the clusters. Most simple oxygen vacancy cluster is $2 \mathrm{Gd}_{\mathrm{Ce}}-1 \mathrm{~V}_{\mathrm{o}} \cdot \bullet$. One oxygen vacancy is assiciated with two dopant $\mathrm{Gd}^{3+}$. In this work, electrically neutral clusters were assumed by the combination of one to four oxygen vacancies and two to eight $\mathrm{Gd}^{3+}$ cations.

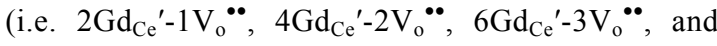
$\left.8 \mathrm{Gd}_{\mathrm{Ce}}{ }^{\prime}-4 \mathrm{~V}_{\mathrm{o}}{ }^{\bullet}\right)$. The biding energy $(\Delta \mathrm{E})$ of electrically neutral clusters is caculated by the following equation.

$\Delta \mathrm{E}=\sum \mathrm{E}_{\text {isolated }}-\mathrm{E}_{\text {cluster }}$

where $E_{\text {cluster }}$ is the energy of a defect cluster, $E_{\text {isolated }}$ is the sum of the defect energies of the corresponding isolated defects $\operatorname{Gd}_{\mathrm{Ce}}{ }^{\prime}$ and $\mathrm{V}_{\mathrm{o}}{ }^{\bullet}$. A higher binding energy menas the high stability of cluster in the matrix of simple fluorite. For the simulation of short range ordering structure, stability of five types of short range ordering of oxygen vacancy clusters was examined. The assumed oxygen vacancy cluster types were re-introduced in Fig.9 and Table 1. In this simulation, The herical chain of type 1 is most stable in all types of oxygen vacancy cluster chains. This type 1 oxygen vacancy cluster chain would be major in the micro-domain. But the authors conclude that so many short oxygen vacancy cluster chains gather into the micro-domain. Then the stability of micro-domain area would be increased in the matrix of fluorite by the formation of huge group of oxygen vacancy clusters. Now we simulate the defect structure consists of oxygen vacancy clusters among micro-domains. After we develop this simulation works, it is expected that oxygen defect structure of doped $\mathrm{CeO}_{2}$ solid electrolytes will be clarified in the viewpoint of crystallography. In our next step, we are going to simulate a diffusion of oxide ion in this nano-heterogeneous structure for a desing of high quality doped $\mathrm{CeO}_{2}$ solid electrolyte. Our challenege of the desing of doped $\mathrm{CeO}_{2}$ on the basis of micro-analysis of actual microstructure will provide us a great opportunity of breakthrough of fuel cell technology.

Since the most stable oxygen vacancy cluster structure was type 1 , we used this type 1 for the calculation of SAEDP. Calculated SAEDP and observed SAEDP were compared in Fig.10. There was no diffuse scattering in the background of calculated electron diffraction pattern on the basis of simple fluorite structure (Fig.10a). On the other hand, the diffuse scattering came up in the background of calculated electron diffraction pattern on the basis of short range ordering model (type 1) as shown in Fig.10b. Also Fig. 10b almost agreed with observed electron diffraction pattern (Fig.10c).

Similar $\mathrm{x}$-ray diffuse scattering ${ }^{29}$ and neutron diffuse scattering ${ }^{30}$ was observed into the $\mathrm{Y}_{2} \mathrm{O}_{3}$ stabilized $\mathrm{ZrO}_{2}$ before. Also influence of the diffuse scattering of the stabilized $\mathrm{ZrO}_{2}$ on long time aging was observed by TEM. $^{31}$ Those analysis suggest that the diffuse scattering is appeared by the short range ordering of oxygen vacancy in the fluorite lattice. It would be attributable to phase separation of tetragonal zirconia and cubic zirconia at micro-scale. On the other hand, in the case of doped $\mathrm{CeO}_{2}$ sintered bodies, the aggregation of dopant cation in the grain provided the diffuse scattering into the background of electron diffraction patterns.

Those results clearly tell us that a combination of ultimate analysis, simulation and processing route design will give us a new design paradigm for development of high quality doped $\mathrm{CeO}_{2}$ solid electrolytes. And we conclude that a control of nano-inhomogeneity in doped $\mathrm{CeO}_{2}$ is a key for design of high quality solid electrolytes for fuel cell application.

(a)

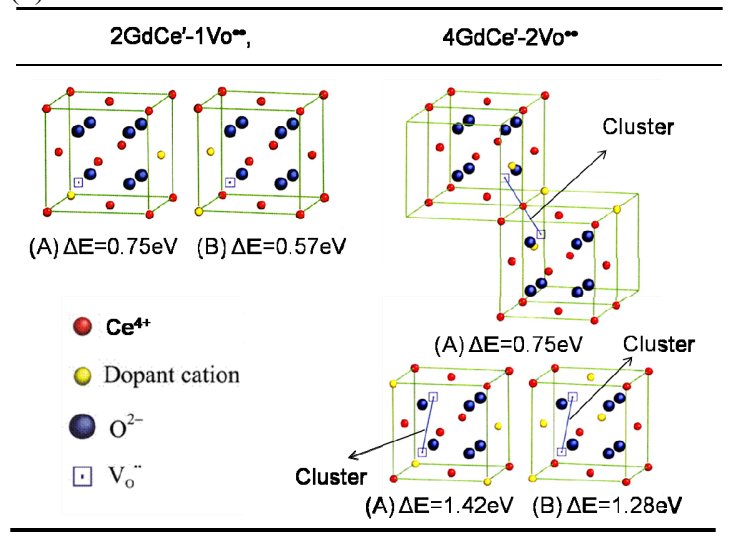

(b)

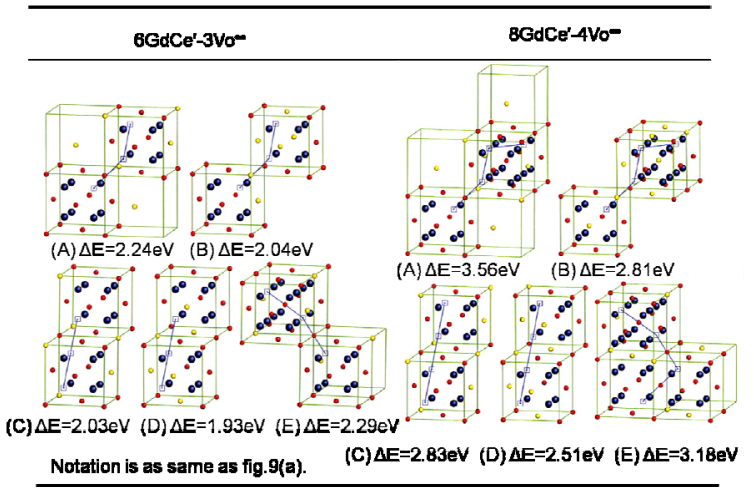

Figure 9 Type of defect clusters in Gd doped $\mathrm{CeO}_{2}$, (a): $2 \mathrm{Gd}_{\mathrm{Ce}^{\prime}}-1 \mathrm{~V}_{\mathrm{o}}{ }^{\bullet}, 4 \mathrm{Gd}_{\mathrm{Ce}^{\prime}}-2 \mathrm{~V}_{\mathrm{o}}{ }^{\bullet}$, and (b): $6 \mathrm{Gd}_{\mathrm{Ce}^{\prime}}-3 \mathrm{~V}_{\mathrm{o}} \cdot \bullet, 8 \mathrm{Gd}_{\mathrm{Ce}}{ }^{\prime}-4 \mathrm{~V}_{\mathrm{o}} \cdot{ }^{[20]}$ 
Table 1 Binding energies of clusters.

\begin{tabular}{|c|c|c|c|c|c|c|c|}
\hline \multirow[b]{2}{*}{ Type } & \multirow{2}{*}{$\begin{array}{l}\text { Chain } \\
\text { of clusters }\end{array}$} & \multirow{2}{*}{ 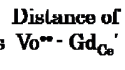 } & \multirow{2}{*}{$\begin{array}{l}\text { Dislante of } \\
\text { Vo"- Vo"* }\end{array}$} & \multicolumn{4}{|c|}{$\Delta E(\mathrm{eV})$} \\
\hline & & & & $n=1$ & 2 & 3 & 4 \\
\hline 1 & & $<3$ & & & & 2.24 & \\
\hline 2 & $\mathrm{C}$ & $<111$ & $110>/ 2$ & 0 & 1.2 & 2.04 & 1 \\
\hline 3 & Straight & $<$ & 12 & 0.75 & 1.42 & 2.03 & 2.83 \\
\hline 1 & Straight & $<111>11$ & $<110>12$ & 0.57 & 1.28 & 1.93 & 2.51 \\
\hline 5 & Curved & $<311>11$ & $<111>/ 2$ & 0.75 & 1.16 & 2.29 & 3.18 \\
\hline
\end{tabular}
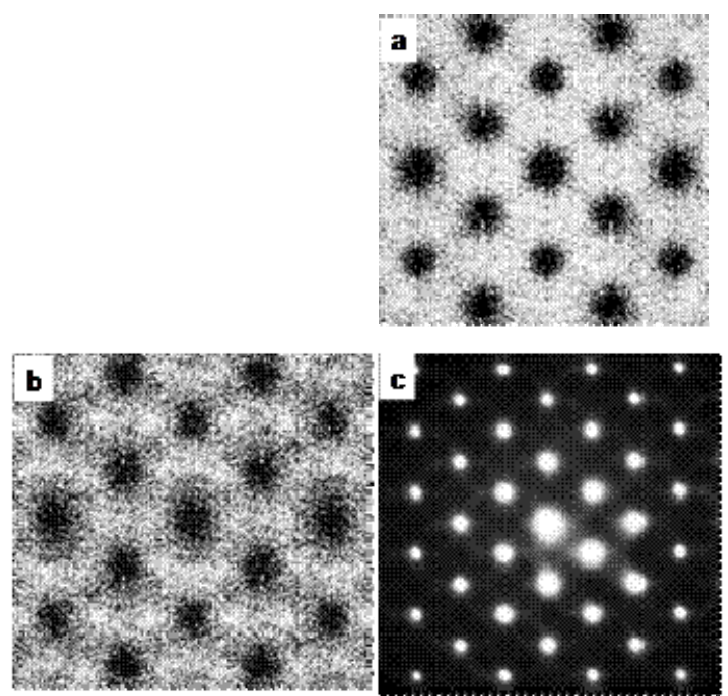

Figure 10 a: [110] calculated electron diffraction pattern on the basis of simple fluorite structure, b: [110] calculated electron diffraction pattern on the basis of type I cluster structure, c: [110] observed electron diffraction pattern.

\section{Influence of nano-inhomogeneity on macro-scale properties of doped $\mathrm{CeO}_{2}$ electrolytes}

To let our design concept mature, the authors have been extensively investigated the influence of nano-structural features on conducting properties in Gd-, $\left.{ }^{[21,}{ }_{26}, 32-36\right] \mathrm{Sm}-{ }^{[33,37,38]}$ Y-, ${ }^{18,19,39-41,45] \quad Y b-,}{ }^{[42]} \mathrm{La}_{-},{ }^{[38,43]} \mathrm{Ho}-{ }^{[44,45]}$ Dy-, ${ }^{[46,47]} \mathrm{Tb}^{[48-52]}$-doped $\mathrm{CeO}_{2}$ electrolytes. For development of doped $\mathrm{CeO}_{2}$, the semi-conducting property has to be depressed. Ho-, and $\mathrm{Tb}$ doped $\mathrm{CeO}_{2}$ are known as semi-conductors which dominant carrier in conduction phenomena is hole or electron. However, $\mathrm{Ho-}$, and $\mathrm{Tb}$-doped $\mathrm{CeO}_{2}$ systems have a wide single phase region of fluorite. In general feeling, the oxide ionic conductor consists of simple fluorite structure. Why did those doped $\mathrm{CeO}_{2}$ systems show the semi-conducting property? To conclude the influence of microstructural features on semi-conducting property of doped $\mathrm{CeO}_{2}$, we observed the micro-structural features of Ho-, and Tb-doped $\mathrm{CeO}_{2}$ specimens sintered at 1450$1500^{\circ} \mathrm{C}$. The microstructural features of Ho-, and Tb-doped $\mathrm{CeO}_{2}$ are quite different as compared with Gd-, Sm-, and Y-doped $\mathrm{CeO}_{2}$. The microstructural features of $\mathrm{Tb}$ doped $\mathrm{CeO}_{2}$ was demonstrated in Fig. 11. The small precipitation in the microstructure was observed in this figure. $\mathrm{Tb}$ M-edge peak from precipitation area was much higher than outside of precipitation area. The $\mathrm{Tb}$ content in the small precipitation area (i.e. white dashed line area of TEM image in Fig.11) was approximately $9 \mathrm{~atm} . \%$ higher than that in the matrix area (i.e. fluorite structure area). Also a big change of Ce M-edge peak was observed in this figure. In the matrix area, Ce M-edge peak has small shoulder as shown in Fig.11.



Figure 11 (a): HR-TEM image recorded from $\mathrm{Tb}_{0.1} \mathrm{Ce}_{0.9} \mathrm{O}_{1.95}$ sintered body, (b) HR-TEM image and (c) EELS $\mathrm{Tb}$ and $\mathrm{Ce} \mathrm{M}$-edge spectra recorded from $\mathrm{Tb}_{0.25} \mathrm{Ce}_{0.75} \mathrm{O}_{0.875}$ sintered body. ${ }^{[50]}$

It is because $\mathrm{Ce}^{4+} \mathrm{M}$-edge peak has this type small shoulder. But $\mathrm{Ce}^{3+}$ does not have this shoulder peak. This indicates that $\mathrm{Ce}^{3+}$ content into the small precipitation area was much higher than that in the matrix area. Based on those microanalysis results, it is concluded that tri-valent cations (i.e. $\mathrm{Tb}^{3+}$ and $\mathrm{Ce}^{3+}$ ) were aggregated into the small precipitation area. And this suggests that a high level oxygen vacancy ordering is around small precipitation area. However, it is very hard to observe those subtle changes of microstructure using standard X-ray diffraction analysis.

As mentioned above, it is concluded that the oxide ionic conductivity and semi-conducting property in doped $\mathrm{CeO}_{2}$ are conspicuously influenced by the subtle changes of microstructure at atomic scale in the specimens.

To maximize the potential of doped $\mathrm{CeO}_{2}$ system in our work, dense Dy doped $\mathrm{CeO}_{2}$ specimens were fabricated using conventional sintering (CS) and pulsed electric current sintering (PECS) methods. Usually, we have fabricated CS specimens with heterogeneous grain growth. To fabricate the homogeneous grain growth specimen, dense sintered bodies were fabricated using PECS method. The microstructures of PECS specimens were shown 
in Fig.12 (b) and (c). To calculate mean grain size, we scanned 500 grains in SEM pictures of sintered body and calculated mean grain size using those data.

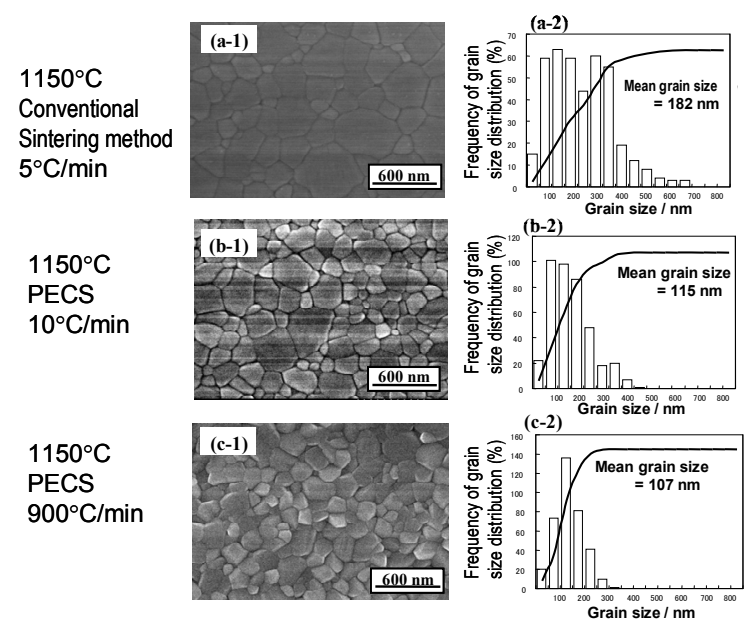

Figure 12 SEM images and grain size distributions recorded from (a) CS and (b) PECS $\mathrm{Dy}_{0.25} \mathrm{Ce}_{0.75} \mathrm{O}_{1.875} \quad$ specimens. Sintering temperature: $1150^{\circ} \mathrm{C}$.

In the case of CS specimen, the grain size distribution in the sintered body is quite broad (Fig.12(a-2)). On the other hand, we successfully fabricated dense PECS specimens which had a quite sharp grain size distribution as shown in Fig.12(c-2). In the case of CS specimen, the compact body is heated by heat elements in the furnace. In this case, the compact body is heated from outside of specimen. On the other hand, PECS specimen is fabricated by the applied direct current. In the case of PECS specimen, almost all grain boundaries can be homogeneously heated by means of this sintering method. Then we can expect homogeneous grain growth in the specimen during the sintering process. Since we can clearly see the difference of grain size distribution between CS and PECS specimens, we concluded that nano-inhomogeneity in the PECS specimen was improved as compared with CS specimen.

The grain size dependence of electrolytic properties (i.e. conductivity, activation energy and oxygen partial pressure $\left(\mathrm{Po}_{2}\right)$ dependence of conductivity) of $\mathrm{Dy}_{0.2} \mathrm{Ce}_{0.8} \mathrm{O}_{1.9}$ sintered body were shown in Fig. 13. ${ }^{[47]}$ The activation energy of sintered bodies was calculated using the data of temperature dependence of conductivity from 400 to $600^{\circ} \mathrm{C}$. The $\mathrm{Po}_{2}$ was changed by the oxygen, air, argon, humidified hydrogen and hydrogen gas flow. The oxygen partial pressure was checked by the external $\mathrm{ZrO}_{2}$ oxygen gas sensor which is heated at $800^{\circ} \mathrm{C}$. The conductivity of Dy doped $\mathrm{CeO}_{2}$ was conspicuously enhanced by the improvement of heterogeneity of microstructure. Also the change of activation energy of sintered bodies corresponded to the change of conductivity. To conclude why the conductivity was improved in the Dy doped $\mathrm{CeO}_{2}$ sintered bodies, the $\mathrm{Po}_{2}$ dependence of conductivity was examined. The $\mathrm{Po}_{2}$ dependence of conductivity was constant in relation to measured $\mathrm{P}_{\mathrm{O} 2}$ as demonstrated in Fig.13(b). This indicates that the improvement of conductivity of PECS specimens is attributable to an enhancement of oxide ionic conductivity in homogeneous microstructure at micrometer scale.



(b)

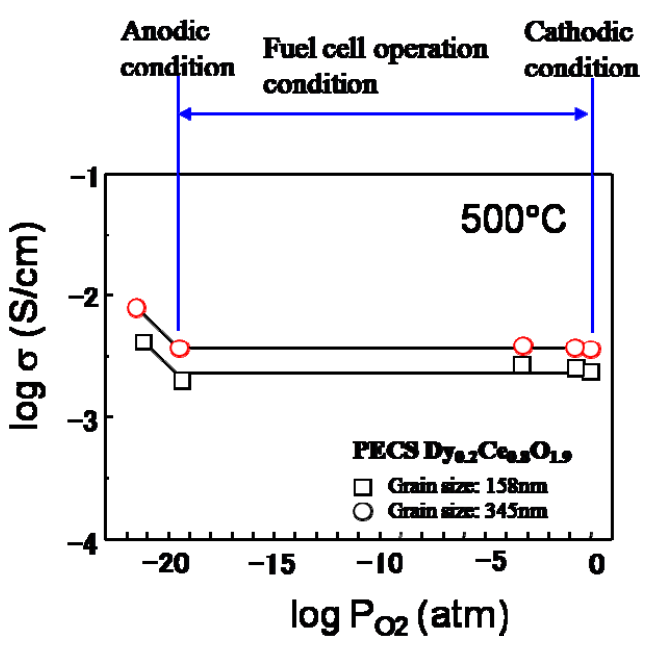

Figure 13 (a): average grain size dependence of conducting properties (i.e. conductivity and activation energy), (b): oxygen partial pressure dependence of conductivity of $\mathrm{Dy}_{0.2} \mathrm{Ce}_{0.8} \mathrm{O}_{1.9}$ sintered body. ${ }^{[47]}$

Also this suggests that the heterogeneity of microstructure at micrometer scale is linked to the heterogeneity of microstructure at nano-scale.

Figure 14 demonstrates the relationship 
between the heterogeneity of microstructure and the conductivity in Dy doped $\mathrm{CeO}_{2}$ specimens.



Figure 14 Schematic diagram of conducting property at $500^{\circ} \mathrm{C}$ vs. micro-structural feature of Dy doped $\mathrm{CeO}_{2}$ sintered specimens. ${ }^{[47]}$

The TEM observation in Fig.14 shows us that the size of micro-domain was minimized in PECS specimen. This result clearly indicates that we can maximize the potential of doped $\mathrm{CeO}_{2}$ solid electrolytes by means of a control of nano-inhomogeneity of micro-structure of doped $\mathrm{CeO}_{2}$. Now the detail micro-structural features in PECS specimen and doped $\mathrm{CeO}_{2}$ thin film devices are under observation. And we try to understand the relationship between nano-scale inhomogeneity and macro-properties such as electrolytic property using doped $\mathrm{CeO}_{2}$ system. In the near future, we expect that we will be able to develop our simulation method and predict an ideal microstructure of doped $\mathrm{CeO}_{2}$ solid electrolytes which has high oxide ionic conductivity and excellent long time durability for fuel cell application.

\section{Summary}

In our short review, we re-introduced a part of our recent results about microanalysis of microstructure, simulation of oxygen defect structure and processing route design for an improvement of macro-property in doped $\mathrm{CeO}_{2}$ solid electrolytes. Many small micro-domains with ordered structure of oxygen vacancy coexisted into the fluorite structure. The electrolytic properties of doped $\mathrm{CeO}_{2}$ become low by the formation of big micro-domains. And we successfully decreased the size of micro-domains in our materials and improved the electrolytic properties of doped $\mathrm{CeO}_{2}$. Based on our all experimental results, it is expected that micro-domain size in doped $\mathrm{CeO}_{2}$ will be minimized into sub-nano scale and the electrolytic properties will be maximized by means of the combination of ultimate analysis, simulation and processing route design. The authors believe that the aforementioned combination approach will provide us a great opportunity for future innovative works in our fuel cell field.

References

[1] N.Yamazoe and N.Miura, MRS Bull., 24(6), 37-43(1999).

[2] U.Nigge, H.D.Wiemhofer, E.W.J.Romer, H.J.M. Bouwmeester, T.R.Schulte, Solid State Ionics, 146(1-2), 163-174(2002).

[3] A.Hashimoto, T.Hibino, M.Sano, Electrochemical and Solid State Letters, 5(2), H1-H3(2002).

[4] N.Izu, W.Shin, I.Matsubara, N.Murayama, Sensors and Actuators B-Chemical, 101(3), 381-386(2004).

[5] T.Hibino, K.Ushiki, Y.Kuwahara, and M.Mizuno, J.Chem.Soc.-Faraday Transactions, 92(21), 4297-4300(1996).

[6] H.Uchida, N.Osada, and M.Watanabe, Electrochemical and Solid State Letters, 7(12), A500-A502(2004).

[7] J.Udagawa, P.Aguiar, N.P.Brandon, Journal of Power Sources, 180(1), 46-55(2008).

[8] S.C.Singhal, "Science and technology of solid oxide fuel cells", MRS Bull., 25(3), 16-21(2000).

[9] B.C.H.Steel, Nature, 414(15), 345-352(2001).

[10] R.M.Ormerod, Chemical Society Reviews, 32(1), 17-28(2003).

[11] I. Riess, Journal of Power Sources, 175, 325-337(2008).

[12] M.Sucipta, S.Kimijima, and K.Suzuki, Journal of the Electrochemical Society, 155(3), B258- B263(2008).

[13] H.Yahiro, Y.Baba, K.Eguchi and H.Arai, Journal of the Electrochemical Society, 135(8), 2077-2080(1988).

[14] V.Buttler, C. R. A. Catlow, B. E. F. Fender, and J.H.Harding, Solid State Ionics, 8, 109-113(1983).

[15] J.Kilner, Solid State Ionics, 129, 13-23(2000).

[16] M.Mogensen, N.M.Sammes, G.A.Tompsett, Solid State Ionics, 129(1-4), 63-94(2000).

[17] V. Esposito, and E. Traversa, Journal of the American Ceramics Society, 91(4), 1037-1051(2008).

[18] T.Mori, J.Drennan, Y.Wang, G.Auchterlonie, J.G.Li, and A.Yago, Science and Technology of Advanced Materials, 4, 213-220(2003).

[19] D.R.Ou, T.Mori, F.Ye, M.Takahashi J.Zou and J.Drennan, Acta Materialia, 54, 3737 3746(2006).

[20] F.Ye, T.Mori, D.R.Ou, A.N.Cormack, R.J.Lewis, and J.Drennan, Solid State Ionics, 179(35-36), 1962-1967(2008).

[21] T.Mori, J.Drennan, D.R.Ou, and F.Ye, International Journal of Nuclear Research (NUKLEONIKA), 51, S11-S18(2006).

[22] R.Gerhard-Anderson and A.S.Nowick, Solid State Ionics, 5, 547-550(1981).

[23] J.A.Kilner, Solid State Ionics, 8, 201-207(1983).

[24] J.Faber, C.Geoffroy, A.Roux, A.Sylverstre and P.Abelard, Appl.Phys.A, 49, 225-232(1989).

[25] J.C.Boivin and G.Mairesse, Chem. Mater, 10, 
2870-2888(1998).

[26] T.Mori, R.Buchanan, D.R.Ou, F.Ye, T.Kobayashi, J.Zou, and J.Drennan, J. Solid State Electrochemistry, 12(7-8), 841-849(2008).

[27] L.Douillard, M.Gautier, N.Thromat, M.Henriot, and M.J.Guittet, 49(23), 1617116180(1994).

[28] A.Travols, N.Boukos, G.Apostolopoulos, and A.Dimoulas, Applied Physics Letters, 82(3), 4053-4055(2003).

[29] T.R.Welberry, R.L.Withers, J.G.Thompson, and B.D.Butter, Journal of Solid State Chemistry, 100, 71-89(1992).

[30] T.Proffen, R.B.Neder and F.Frey, Acta Cryst., B52, 59-65(1996).

[31] Junya Kondoh, Shiomi Kikuchi, Yoichi Tomii and Yasuhiko Ito, Journal of the Electrochemical Society, 145(5), 1536-1550 (1998).

[32] D. R. Ou, T. Mori, F. Ye, J. Zou, G. Auchterlonie and J. Drennan, Electrochemical and Solid-State Letters, 10(1), 1-3(2007).

[33] R.Buchanan, T.Mori, Y.Wang, D.R.Ou, F.Ye, and J.Drennan, Transactions of the Materials Research Society of Japan, 30(4), 955-958(2005). [34] T.Mori T, and J.Drennan, J.Electroceramics, 17(2-4), 749-757(2006).

[35] D.R.Ou, T.Mori, F.Ye, J.Zou, and J.Drennan, Physical Review B, 77, article number 024108-1 024108-8(2008).

[36] F.Ye, T.Mori, D.R.Ou, J.Zou, G.Auchterlonie, and J.Drennan, Solid State Ionics, 179(21-26), 827-831(2008).

[37] T.Mori, J.Drennan, Y.Wang, J.G.Li, and T.Ikegami, Journal of Thermal Analysis and Calorimetry, 70(2), 309-319(2002).

[38] T.Mori, J.Drennan, J.H.Lee, J.G.Li, and T.Ikegami, Solid State Ionics, 154, Special Issue Part B, 461-466(2002).

[39] Y.Wang, H.Kageyama, T.Mori, H.Yoshikawa, and J.Drennan, Solid State Ionics, 177(19-25), 1681-1685(2006).

[40] D.R.Ou, T.Mori, F.Ye, T.Kobayashi, J.Zou, G.Auchterlonie, and J.Drennan, Applied Physics Letters, 89(17), 1911-1913(2006).

[41] D.R.Ou, T.Mori, F.Ye, J.Zou, and J.Drennan, Electrochemical and Solid-State Letters, 10(1), 1-3(2007).

[42] F.Ye, T.Mori, D.R.Ou, M.Takahashi, J.Zou, and J.Drennan, Journal of the Electrochemical Society, 154(2), B180-B185 (2007).

[43] T.Mori, J.Drennan, Y.Wang, J.H.Lee, J.G.Li, and T.Ikegami, Journal of the Electrochemical Society, 150(6), A665-A673(2003).

[44] D.R.Ou, T.Mori, F.Ye, J.Zou, G.Auchterlonie, and J.Drennan, Journal of the Electrochemical Society, 154(7), B616-B622 (2007).

[45] D. R. Ou, T. Mori, F. Ye, J. Zou, and J. Drennan, Renewable Energy, 33, 197-200(2008).

[46] Y.Wang, T.Mori, J.G.Li, and J.Drennan, Journal of the European Ceramic Society, 25(6), 949-956(2005).

[47] T.Mori, T.Kobayashi, Y.Wang, J.Drennan,
T.Nishimura, J.G.Li, and H.Kobayashi, Journal of the American Ceramic Society, 88(7), 19811984(2005).

[48] F.Ye, T.Mori, and D.R.Ou, Journal of Nanoscience and Nanotechnology, 7(7), 25212525 (2007).

[49] F.Ye, T.Mori, D.R.Ou, J.Zou, and J.Drennan, Materials Research Bulletin, 42(5), 943949(2007).

[50] F.Ye, T.Mori, D.R.Ou, J.Zou, G.Auchterlonie, and J.Drennan, Journal of Applied Physics, 101(11), article number: 113528-1 -113528-5(2007).

[51] F.Ye, T.Mori, D.R.Ou, J.Zou, and J.Drennan, Materials Research Bulletin, 43(3), 759764(2008).

[52] F. Ye, T. Mori, D. R. Ou, J. Zou and J. Drennan, Renewable Energy, 33, 331-335(2008).

\section{Acknowledgement}

Our work was supported by the Grant-In-Aid of Ministry of Education, Science, Sports, and Culture (MEXT), Japan; Scientific Research on Priority Area, 'Nanoionics (439)'. The authors appreciate to this funding support for development of our work.

(Received January 7, 2010; Accepted April 2, 2010) 